\title{
Incidence of Retinopathy of Prematurity and Its Association with Oxygen Therapy in Preterm Low Birth Weight Babies
}

\author{
Pal $A K^{1}$, Sur $S^{2}$, Pal J ${ }^{3}$, Gupta $A K^{4}$
}

\begin{abstract}
Introduction: The objectives of this study were to study the incidence and risk factors of retinopathy of prematurity (ROP) among preterm low birth weight babies and its association with oxygen therapy. Material and Methods: During one year study period, 50 neonates, who had fulfilled the inclusion criteria (born at gestational age $\leq 35 \mathrm{wks}$ ), were included in the present study. They were examined by indirect ophthalmoscopy by an ophthalmologist in NICU or ophthalmology outdoor. Staging of ROP was done according to the International classification. Data obtained from this study were entered in Microsoft Excel and subsequently analysed in SPSS version 20.0. Results: Among study population, 12 neonates (24\%) showed evidence of retinopathy of prematurity, and Stage 2 ROP was most common $(41.7 \%)$ within this group. Those neonates who had born $\leq 28$ wks gestational age, showed more incidence $(75 \%)$ of ROP. There was significant association between ROP and prematurity, low birth weight, mechanical ventilation, duration and concentration of oxygen therapy. Conclusion: Apart from prematurity and low birth weight, oxygen therapy also carries significant risk for ROP. Thus, judicious use of oxygen in premature babies can reduce incidence of ROP significantly.
\end{abstract}

Key words : Oxygen, Preterm, ROP, Ventilator

\section{Introduction}

A ssociation between oxygen and retinopathy of prematurity (ROP) has been known for a long time. Tin and colleagues reported a decrease incidence of ROP in whom oxygen is maintained between $70 \%$ - $90 \%$ versus $88 \%$ - $98 \%^{1}$. Aston and others ${ }^{2}$ had suggested that the susceptibility of the growing vessels in the retina to hyperoxia probably related to unique anatomic and developmental relationship between the retinal and choroidal circulation $^{3}$. Choroidal vessels supply the outer half of the retina by diffusion. They are more permeable, and have a high venous $\mathrm{PaO}_{2}$, lack the ability of autoregulation in response to hyperoxia. $\mathrm{PaO}_{2}$ level is raised across the thickness of the retina and retinal vessels respond by constriction. However a meta-analysis by Askie and Hendersonsmart $^{4}$ of 5 randomized control trials conducted in preterm infants in which ambient $\mathrm{O}_{2}$ concentration were targeted to achieve either a lower or higher blood $\mathrm{O}_{2}$ range was unable to determine the optimal
'Dr. AK Pal, MD-PGT, Department of Paediatrics, Vivekananda Institute of Medical Sciences, Kolkata, India, ${ }^{2}$ Dr. S Sur, MD-PGT, Department of Paediatrics, Vivekananda Institute of Medical Sciences, Kolkata, India, ${ }^{3}$ Dr. J Pal, PGT, Department of Preventive and Social Medicine, Institute of Hygiene and Public Health, Kolkata, India, ${ }^{4}$ Dr. AK Gupta, Professor and Head of the Department, Department of Paediatrics, Vivekananda Institute of Medical Sciences, Kolkata, India.

\section{Address for correspondence: \\ Dr. Somen Sur \\ 67/E/2, GT Road (West), PO Mullickpara, \\ PS Serampore, Dist. Hooghly, \\ West Bengal, India, Pin: 712203. \\ E-mail: somensur29@gmail.com \\ Tel No; +919433428988}

\section{How to cite}

Pal AK, Sur S, Pal J, Gupta AK. Incidence of Retinopathy of Prematurity and Its Association with Oxygen Therapy in Preterm Low Birth Weight Babies. J Nepal Paediatr Soc 2015;35(3):247-252.

doi: http://dx.doi.org/10.3126/jnps.v35i3.12964

This work is licensed under a Creative Commons Attribution 3.0 License.

\section{(c) (i)}

target range for maintaining blood $\mathrm{PaO}_{2}$ levels in preterm infants.

The STOP-ROP study ${ }^{5}$ was launched to see if development from prethreshold to threshold ROP can be reduced by hypoxia. Two groups were studied among babies with $\mathrm{SaO}_{2}<94 \%$ in room air - the standard group with $\mathrm{SaO}_{2}$ between $89 \%-95 \%$ and the high saturation group with $\mathrm{SaO}_{2}$ between 96\%-99\%. Although a tendency for a better outcome regarding the eye was found in low saturation group, these babies had significantly more lung problems and 
also needed longer time on oxygen and more days in hospital. Several studies that looked at the effect of gradual versus abrupt weaning of oxygen on the incidence of ROP were unable to find any difference between the two ${ }^{6}$.

In this study preterm babies having gestational age $\leq 35$ wks were included. Screening was done at 4 wks of chronological age or at 31 week of gestational age (whichever was later) by indirect ophthalmoscope to evaluate the incidence and risk factors of ROP in preterm and/or low birth weight neonate and to associate incidence with oxygen therapy.

\section{Material and Methods}

This study was done at the Vivekananda Institute of Medical Sciences, Kolkata (Neonatal intensive care unit, Department of Paediatrics with help of department of Ophthalmology) over a one year period. It was a prospective observational study. Babies born with gestational age $</=35$ weeks were included in this study. The number of neonates that fulfilled the inclusion criteria was 50 .

Binocular Indirect ophthalmoscope, Infant speculum and Kreissig scleral depressor were used for the tests.

Babies admitted to the neonatal unit with gestational age of $\leq 35$ weeks, were screened for ROP by an ophthalmologist by indirect ophthalmoscopy. Babies were examined at four weeks after birth or 31 weeks gestational age, whichever was later. Mydriasis was achieved by using $1 \%$ Tropicamide thrice at intervals of $5 \mathrm{~min}$ followed by $1-2$ drops of $2.5 \%$ or $5 \%$ phenylephrine twice at intervals of $5 \mathrm{~min}$. Staging of ROP was done according to the International classification?.

Data obtained from this study were entered in Microsoft Excel and subsequently analysed in SPSS version 20.0. Descriptive data was analysed as simple frequency, percentages, univariate analysis, odds ratio etc. and presented in tables and diagrams. For the entire statistical test applied, $p$ value $<0.05$ had been considered to reject the null hypothesis.

Ethical clearance obtained from hospital and informed consents of parent were also obtained.

\section{Results}

Table 1: Distribution of study population according to the occurrence of ROP $(n=50)$

\begin{tabular}{|c|c|c|}
\hline ROP & Frequency & Percent \\
\hline Negative & 38 & $\mathbf{7 6}$ \\
\hline Positive & 12 & 24 \\
\hline Total & $\mathbf{5 0}$ & $\mathbf{1 0 0}$ \\
\hline
\end{tabular}

In the babies screened, $24 \%$ had some evidence of ROP and $76 \%$ had no ROP detected.

Table 2: Distribution of the study population $(n=12)$ depending on stage of ROP

\begin{tabular}{|c|c|c|}
\hline Stage & Frequency & Percent \\
\hline 1 & 3 & 25 \\
\hline 2 & 5 & 41.7 \\
\hline 3 & 4 & 33.3 \\
\hline Total & 12 & 100 \\
\hline
\end{tabular}

$25 \%$ had stage 1, $41.7 \%$ had stage 2 and $33.3 \%$ had stage 3 . In case of ROP in both eyes, the maximum stage of ROP was taken into consideration for analysis.

Table 3: Distribution of study population ( $n=50)$ depending on gestational age (GA)\& incidence of ROP

\begin{tabular}{|c|c|c|c|}
\hline Gestational age & No ROP & ROP & \% \\
\hline$\leq 28$ wk & 4 & 3 & $75 \%$ \\
\hline $29-30$ wk & 16 & 6 & $37.5 \%$ \\
\hline $31-32$ wk & 17 & 3 & $17.6 \%$ \\
\hline $33-35$ wk & 13 & 0 & $0 \%$ \\
\hline
\end{tabular}

The incidence of ROP 75\%, 37.5\%, $17.6 \%$ among $\leq 28$ wk, 29-30 wk, 31-32 wk GA respectively.

Table 4: Table showing relationship of ROP with gestational age of the babies

\begin{tabular}{|c|c|c|c|c|c|}
\hline Gestational Age & Negative & Positive & Total & p-Value & Significance \\
\hline$<=28$ & $1(2.6 \%)$ & $3(25 \%)$ & $4(8 \%)$ & & \multirow{2}{*}{0.008} \\
\cline { 1 - 3 } $29-30$ & $10(26.3 \%)$ & $6(50 \%)$ & $16(32 \%)$ & & \\
\cline { 1 - 3 } $31-32$ & $14(36.8 \%)$ & $3(25 \%)$ & $17(34 \%)$ & & \\
\hline $33-35$ & $13(34.2 \%)$ & $0(0 \%)$ & $13(26 \%)$ & & \\
\hline Total & $38(100 \%)$ & $12(100 \%)$ & $50(100 \%)$ & & \\
\hline
\end{tabular}

In Chi Square test gestational age of the babies was found to be a significant risk factor ( $p$ value -0.008 ) in occurrence of ROP. 
Table 5: Table showing strength of association of ROP with gestational age of the babies

\begin{tabular}{|c|c|c|c|}
\hline Gestational Age & ROP & No ROP & OR \\
\hline$<=28$ weeks & 3 & 1 & 12.33 \\
\hline$>28$ weeks & 9 & 37 & Ref \\
\hline
\end{tabular}

There is 12.33 times greater risk of development of ROP in babies with gestational age of <=28 weeks than babies with gestational age of $>28$ weeks.

Table 6: Distribution of population $(n=50)$ depending on birth weight \& incidence of ROP

\begin{tabular}{|c|c|c|c|}
\hline Birth weight & No ROP & ROP & TOTAL \\
\hline$<1000 \mathrm{gm}$ & $1(16.7 \%)$ & $5(83.3 \%)$ & $6(100 \%)$ \\
\hline $1000-1499 \mathrm{gm}$ & $30(81.1 \%)$ & $7(18.9 \%)$ & $37(100 \%)$ \\
\hline $1500-1999 \mathrm{gm}$ & $7(100 \%)$ & $0(0 \%)$ & $7(100 \%)$ \\
\hline TOTAL & $\mathbf{3 8}$ & $\mathbf{1 2}$ & $\mathbf{5 0}$ \\
\hline
\end{tabular}

The incidence of ROP was $83.3 \%$ among < 1000gm, $18.9 \%$ among $>1000$ gm.

Table 7: Table showing relationship of ROP with birth weight of the babies

\begin{tabular}{|c|c|c|c|c|c|}
\hline Birth Weight & Negative & Positive & Total & p-value & Significance \\
\hline$<1000$ & $1(2.6 \%)$ & $5(41.7 \%)$ & $6(12 \%)$ & & \multirow{2}{*}{ Significant } \\
\cline { 1 - 4 } $1000-1499$ & $30(78.9 \%)$ & $7(58.3 \%)$ & $37(74 \%)$ & & \\
\hline $1500-1999$ & $7(18.4 \%)$ & $0(0 \%)$ & $7(14 \%)$ & & \\
\hline Total & $\mathbf{3 8 ( 1 0 0 \% )}$ & $\mathbf{1 2 ( 1 0 0 \% )}$ & $\mathbf{5 0 ( 1 0 0 \% )}$ & & \\
\hline
\end{tabular}

In Chi Square test birth weight was found to be a significant risk factor for occurrence of ROP ( $p$ value 0.001)

Table 8: Table showing strength of association of ROP with birth weight of the babies

\begin{tabular}{|c|c|c|c|}
\hline Birth Weight & ROP & No ROP & OR \\
\hline$<1000$ & 5 & 1 & 26.4 \\
\hline$>=1000$ & 7 & 37 & Ref \\
\hline
\end{tabular}

There is 26.4 times greater risk of occurrence of ROP among the babies with birth weight $<1000$ gram than those with birth weight $>1000$ gram

Table 9: Table showing relationship between type of oxygen therapy and ROP

\begin{tabular}{|c|c|c|c|c|c|}
\hline Type of oxygen therapy & Negative & Positive & Total & p-value & Significance \\
\hline Ventilation & $5(13.2)$ & $11(91.7)$ & $16(32)$ & \multirow{3}{*}{$<0.001$} & \multirow{3}{*}{ Significant } \\
\hline Only CPAP & $7(18.4)$ & $1(8.3)$ & $8(16)$ & & \\
\hline Only free low oxygen & $26(68.4)$ & $0(0)$ & $26(52)$ & & \\
\hline Total & $38(100)$ & $12(100)$ & $50(100)$ & & \\
\hline
\end{tabular}

Sixteen babies were ventilated, among them 11 developed ROP (91.6\%). Eight babies received CPAP only \& 1 developed ROP (8\%). Among the babies receiving only free flow oxygen no one developed ROP. On analysis the Chi Square found that test ventilation was found to be a significant risk factor ( $p$-value $<0.001$ ) for development of ROP.

Table 10: Table showing strength of association of development of ROP with type of oxygen therapy received by the babies

\begin{tabular}{|c|c|c|c|}
\hline Type of oxygen therapy & ROP & No ROP & OR \\
\hline $\begin{array}{c}\text { Ventilation } \\
\begin{array}{c}\text { Other forms of oxygen } \\
\text { therapy }\end{array}\end{array}$ & 11 & 5 & Ref \\
\hline
\end{tabular}

There was 72.6 times greater risk of development of ROP in babies who had received oxygen therapy in form of ventilation than those who had received oxygen therapy in other forms (like CPAP/only free flow oxygen). 
Table 11: Distribution of study population $(n=50)$ depending on duration of oxygen therapy and incidence of ROP

\begin{tabular}{|c|c|c|c|}
\hline \multirow{2}{*}{$\begin{array}{c}\text { Duration of } \\
\text { Oxygen duration }\end{array}$} & \multicolumn{2}{|c|}{ ROP } & \multirow{2}{*}{ Total } \\
\cline { 2 - 3 } & YES & NO & \\
\hline$<=150$ Hours & $3(8.6 \%)$ & $32(91.4 \%)$ & $35(100 \%)$ \\
\hline$>150$ Hours & $9(60 \%)$ & $6(40 \%)$ & $15(100 \%)$ \\
\hline Total & $12(24 \%)$ & $38(76 \%)$ & $50(100 \%)$ \\
\hline \multicolumn{2}{|c|}{ Chi-Square=15.226, $\mathrm{df}=1, \mathrm{P}=0.000}$, \\
\hline
\end{tabular}

Among the babies who had received oxygen therapy of $>150$ hours, $60 \%$ had developed some form of ROP. Among the babies who had received oxygen therapy of <=150 hours, only $8.6 \%$ of them had developed ROP. Chi-square test shows that this difference is statistically significant, that means duration of oxygen therapy is a significant risk factor for development of ROP.

Table 12: Table showing strength of association between oxygen therapy and incidence of ROP in population $(n=50)$

\begin{tabular}{|c|c|c|c|c|}
\hline \multirow{2}{*}{$\begin{array}{c}\text { Duration of } \\
\text { oxygen therapy }\end{array}$} & \multicolumn{2}{|c|}{ ROP } & \multicolumn{2}{c|}{ Analysis } \\
\cline { 2 - 5 } & Present & Absent & OR & Cl \\
\hline$<=150$ Hours & 3 & 32 & 1 & - \\
\hline$>150$ Hours & 9 & 6 & 16 & $\begin{array}{c}3.326- \\
76.973\end{array}$ \\
\hline
\end{tabular}

There is 16 times higher risk of developing ROP if the duration of oxygen therapy is $>150$ hours than in those where duration of oxygen therapy is $\leq 150 \mathrm{hrs}$. This is statistically significant as $\mathrm{Cl}$ falls between 3.326 and 76.973 .

Table 13: Distribution of study population $(n=50)$ according to concentration of oxygen delivered and incidence of ROP

\begin{tabular}{|c|c|c|c|}
\hline $\begin{array}{c}\text { Concentration of } \\
\text { oxygen delivered }\end{array}$ & Affected & $\begin{array}{c}\text { Not } \\
\text { Affected }\end{array}$ & Total \\
\hline$<30 \%$ & 0 & 18 & 18 \\
\hline $30-40 \%$ & 2 & 12 & 14 \\
\hline$>40 \%$ & 10 & 8 & 18 \\
\hline Total & $\mathbf{1 2}$ & $\mathbf{3 8}$ & $\mathbf{5 0}$ \\
\hline
\end{tabular}

Chi Square 16.235, $p$-value $0.000(<0.05)$

Above table shows that concentration of oxygen delivery was a significant risk factor for development of ROP.
Table 14:Distribution of study population $(n=50)$ according to requirement of blood transfusion (for anaemia) and incidence of ROP

\begin{tabular}{|c|c|c|c|}
\hline $\begin{array}{c}\text { Requirement of } \\
\text { blood transfusion for } \\
\text { anaemia }\end{array}$ & Affected & $\begin{array}{c}\text { Not } \\
\text { Affected }\end{array}$ & Total \\
\hline Yes & 2 & 6 & 8 \\
\hline No & 10 & 32 & 42 \\
\hline Total & $\mathbf{1 2}$ & $\mathbf{3 8}$ & $\mathbf{5 0}$ \\
\hline
\end{tabular}

Chi Square 0.005, p value $0.942(>0.05)$

Above table shows that blood transfusion was not a statistically significant risk factor for development of ROP in the present study.

Table 15: Distribution of study population $(n=50)$ according to occurrence of apnoea (once/ more) and incidence of ROP

\begin{tabular}{|c|c|c|c|}
\hline $\begin{array}{c}\text { Apnoea[Once/ } \\
\text { More] }\end{array}$ & Affected & $\begin{array}{c}\text { Not } \\
\text { Affected }\end{array}$ & Total \\
\hline Yes & 7 & 17 & 24 \\
\hline No & 5 & 21 & 26 \\
\hline Total & $\mathbf{1 2}$ & $\mathbf{3 8}$ & $\mathbf{5 0}$ \\
\hline
\end{tabular}

Chi Square 0.675, p value 0.411 (>0.05)

Above table shows that apnoea was not a statistically significant risk factor for development of ROP in this study.

\section{Discussion}

Retinopathy of prematurity is a vasoproliferative disorder occurring predominantly in premature infants. Normal vasculature of the developing retina is interrupted due to some injury. After a latent period, there is neovascularization. If this new vessel formation is abnormal, it leads to progressive retinopathy, ultimately resulting in retinal detachment and blindness ${ }^{8}$. ROP was first reported in 1942 by Terry ${ }^{9}$. In spite of an intense search of a specific cause, it was not until 1951 that a pediatrician in Melbourne, Australia provided the first link between the use of oxygen and ROP $^{10}$. Several report subsequently suggested that an inspired oxygen concentration less than $40 \%$ was unlikely to lead to ROP ${ }^{11,12}$. The decline in use of greater than $40 \%$ supplemental oxygen for premature infant in 1950 resulted in the declining incidence of ROP ${ }^{12,13}$. The 1960s were associated with enormous advances in the field of neonatology. It was then possible to resuscitate and ventilate tiny premature infants. Increased survival of these small infants together with the liberal use of oxygen led to resurgence of ROP ${ }^{14}$. 
At present, particularly in developed nations, incidence of ROP is reduced by judicial use of oxygen therapy. In United States, around $10 \%$ of preterm babies are suffering from blindness, which can be $20 \%$ or even higher in developing countries ${ }^{15,16,17,18}$.

Most common causes of ROP are premature birth and low birth weight ${ }^{19,20}$. Incidence of ROP increases with lower gestational age ${ }^{21}$.

Incidence of ROP in the present study was found to be $24 \%$ much lower than Rekha et al. ${ }^{22}$ in 1996 but in more recent studies the incidence were more like this result eg Gupta et al. ${ }^{23} 2004$ or Chowdhury et al. [24] 2009. Stage 2 (41.7\%) was most common. In the present study, ROP was more prevalent (75\%) in neonates born $<28$ wk gestational age comparable with study of Saeidi et al. ${ }^{25}$, which was significant statistically (p 0.008), comparable with Hakeem et al., Karna et al. ${ }^{21,26}$. Prevalence of ROP was more in $<1000$ gram population (83.3\%) comparable with Freeman et al., Kistner et al. ${ }^{20,27}$. There was also significant association between ROP and low birth weight ( $p$ $0.001)$, mechanical ventilation $(p<0.001)$, duration of ventilation ( $p$ 0.000), comparable with Freeman et al. ${ }^{27}$, Shah et al. ${ }^{28}$, Mokhtari et al. ${ }^{29}$ respectively. Askie et al. through NeOProM study also concluded that high level of oxygenation increased the morbidity burden of retinopathy of prematurity ${ }^{30}$. In the present study, it is shown that increasing the concentration of oxygen delivery carries significant risk [p 0.000] for development of ROP.

Though Hassel et al. ${ }^{31}$ and Banerjee et al. ${ }^{32}$ had shown significant association between blood transfusion and development of ROP, the present study could not show significant association between them. Similarly, this study could not find out any significant risk association between apnoea and development of ROP, though according to Chattopadhyay et al. ${ }^{33}$ and Aggarwal et al. ${ }^{34}$, apnoea carried significant risk factor for development of ROP. Observation of insignificant relationship between apnoea and blood transfusion with ROP in the present study may probably be due to consideration of a small sample size.

\section{Conclusion}

The incidence of ROP was found around $24 \%$ in this study. The most important risk factors which were found to be significantly predisposing to development of ROP included gestational age $<=28$ weeks, birth weight $<1000$ gram, ventilation as a type of oxygen therapy, use of increasing concentration of oxygen delivery and oxygen therapy for $>150$ hours.
Thus, one should be cautious regarding judicious use of oxygen therapy in premature babies particularly during neonatal resuscitation (to use blender, to guide oxygen concentration as per $\mathrm{SPO}_{2}$ monitoring), to try to avoid prolonged ventilation, and to target $\mathrm{SPO}_{2} 85-$ $95 \%$. By ensuring these steps, one can cut down the incidence of ROP significantly in future.

Further study with large sample size would be required in future to draw a more firm conclusion.

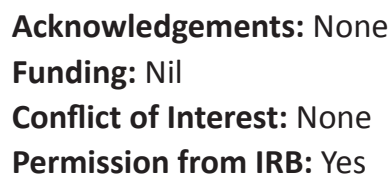

\section{References}

1. Tin W, Milligan DW, Pennefather P, et al. Pulse oximetry, severe retinopathy and outcome at one year in babies of less than 28 wk gestation. Arch Dis Child Fetal Neonatal, Ed 2001;84: F106-F110.

2. Ashton N. Animal experiments in retrolental fibroplasia.TransAmAcadOphthalmolotolaryngeal 1954;58:51-4.

3. Dollory CT, Bulpitt CJ, Kohner EM. Oxygen supply to the retina from the retinal and choroidal circulation at normal and increased arterial oxygen tension. Invest Ophthalmol 1969;8:588-94.

4. Askie LM, Henderson-Smart DJ. Early versus late discontinuation of oxygen in preterm or low birth weight infants. Cochrane Database Syst Rev 2001;(4):CD001076

5. The STOP-ROP Multicentre Study Group. Supplemental therapeutic oxygen for prethreshold retinopathy of prematurity (STOP-ROP), a randomized controlled trial. Primary outcome. Pediatrics 2000;105:295-310.

6. Askie LM, Henderson-Smart DJ. Gradual versus abrupt discontinuation of oxygen in preterm or low birth weight infants. Cochrane Database Syst Rev 4; 2001: CD001075

7. International Committee for the Classification of Retinopathy of Prematurity. The International Classification of Retinopathy of Prematurity revisited. Arch Ophthalmol 2005;123(7):991-99.

8. Harnett ME, Penn JS. Mechanisms and management of retinopathy of prematurity. N Eng J Med 2013;368:1162-63.

9. Terry TL. Extreme prematurity \& fibroblastic overgrowth of persistent vascular sheath behind each crystalline lens. Am J Ophthalmol 1942;25:203-204. 
10. Cambell K. Intensive oxygen therapy as a possible cause of retrolental fibroplasia. A clinical approach. Med J 1951;48-54.

11. Guy LP, Lamman JT, Dancis J. The possibility of total elimination of retrolental fibroplasias by oxygen restriction. Pediatrics 1956;17:247-51.

12. Silverman WA. Retinopathy of Prematurity : oxygen dogma challenged. Arch Dis Child 1982;57:731-33.

13. Gross KW. Cost of preventing retrolental fibroplasia. Lancet 1973;2:954-56.

14. James S, Lanman JT. History of oxygen therapy and retrolental fibroplasia. American Academy of Pediatrics, Committee on Fetus and Newborn with the collaboration of special consultants. Pediatrics 1976;57:591-42.

15. Shah PK, Narendran V, Kalpana N. Aggressive posterior retinopathy of prematurity in large preterm babies in South India. Arch Dis Child Fetal Neonatal Ed 2012;97:371-75.

16. Darlow BA, Gilbert CE, Quiroga AM. Setting up and improving retinopathy of prematurity programs: interaction of neonatology, nursing and ophthalmology. Clin Perinatology 2013;40:215-27.

17. Owen LA, Harnett ME. Current concepts of oxygen management in retinopathy of prematurity. J Ophthal Vis Res 2014;9(1):94-100.

18. Crim N, Knoll EG et al. impact of changing oxygenation policies on ROP in a neonatal unit in Argentina. Br J Ophthal 2012;96:1456-561.

19. Gunn TR, Easdown J, Outrbridge EW, et al. Risk factor in retrolental fibroplasia. Pediatrics 1980;65:1096-1100.

20. Lundgren $P$, Kistner $A$ et al. Low birth weight is a risk factor for severe retinopathy of prematurity depending on gestational age. PLOS-ONE, 2014;9(10):e109460.

21. Angell L, Karna $P$ et al. retinopathy of prematurity and risk factors: a prospective cohort study. BMC Pediatr, 2005;5:18.

22. Rekha S, Battu RR. Retinopathy of prematurity, incidence and risk factors. Indian Pediatr, 1996;33:999-1003.

23. Gupta VP, Dhaliwal U, Sharma R, Gupta P, Rohitgi J. Retinopathy of prematurity - risk factors. Indian J Pediatr 2004;71:887-91.
24. Choudhury S, Patwardhan V, Vaidya U, Kadam S, Kamat A. Retinopathy in a tertiary care Centre incidence, risk factors and outcome. Indian Pediatr 2009;46:219-24.

25. Saeidi R, Ahmadi S, HashemzadehA et al. Prevalence and predisposing factors of retinopathy of prematurity in very low birth weight infants discharged from NICU. Iran J Pediatr 2009;19(1):5963.

26. Hakeem AH, Mohamed GB, Othman MF. Retinopathy of prematurity: a study of prevalence and risk factors. Middle East Afr J Ophthalmol, 2012;19(3):289-94.

27. Freeman N, Bekker A, Harvey J et al. Prevalence of and risk factors for retinopathy of prematurity in a cohort of preterm infants treated exclusively with non-invasive ventilation in the first week after birth. Singapore Med Assoc J 2013;103(2):96-100.

28. Shah VA, Yeo CL, Ling YLF et al. Incidence,risk factors of retinopathy of prematurity among very low birth weight infant in Singapore. Ann Acad Med Singapore 2005;34:169-78.

29. Pishva N, Mokhtari MB, Atterzadeh A et al. Incidence and risk factors of retinopathy of prematurity among preterm infants in Shiraz/Iran. Iran J Pediatr 2010;20(3):303-307.

30. Askie LM, Darlow BA et al.NeOProM: Neonatal oxygenation perspective Meta analysis collaboration study protocol. BMC Pediatr 2011;11:6.

31. Hessel L, Eberl $W$ et al. Blood transfusion. Iron load and Retinopathy of Prematurity. Eur J Pediatr 1997;156(6):465-70.

32. Banerjee J, Asamoah F et al. Association between blood transfusion and development of retinopathy of prematurity- review of literature and Meta analysis. Arch Dis Child 2014;99:A184-85.

33. Chattopadhyay MP, Pradhan A et al. Incidence and risk factors for retinopathy of prematurity in neonates. Indian Pediatr 2015;52:157-158.

34. Aggarwal R, Deorari AK et al. Changing profile of retinopathy of prematurity. J Trop Pediatr 2002;48:239-42. 